\title{
Protein Information Resource
}

National Cancer Institute

\section{Source}

National Cancer Institute. Protein Information Resource. NCI Thesaurus. Code C48785.

An integrated public bioinformatics resource to support genomic and proteomic research

and scientific studies; provides protein databases and analysis tools freely accessible to the scientific community. Today, PIR offers a wide variety of resources mainly oriented to assist the propagation and standardization of protein annotation. Among these are: PIRSF, which provides curated protein families with rules for functional site and protein name; iProLink, that supports text mining in the area of literature-based database curation, named entity recognition, and protein ontology development; and ProClass, which contains value-added annotation reports for UniProt proteins. 